\title{
Global Communications and Changing Perspectives: The World as a World Society
}

\author{
Milorad Djurić \\ College of Social Work, \\ Speech and Language Therapy and Occupational Therapy (Department of Social Work), Belgrade, Serbia
}

\begin{abstract}
In this paper we will analyze the world as a world society. Our assumption is that, thanks to global communications, the world has become a unique social field. Therefore, it is necessary to make an analysis of the changes that have occurred in the society-state relationship. In the contemporary understanding, societies are constituted as relatively closed, self-referential systems, in which the world of life is framed by the borders of national states. Intensifying and extending the communication process has relativized the boundaries of such closed systems, creating an opportunity for the establishment of a world society. However, the practical political (infra)structure is still fixed on old patterns and, objectively, lags behind this change, creating a legitimacy deficit in the political field. So it is necessary to look at the world from a new perspective.
\end{abstract}

Keywords: communications, world, society, state, boundaries, environment, system, perspective

\section{Introduction: The World as an Entire Reality}

Regardless of whether we are facing climate change, economic crises, scientific and technological discoveries, terrorist attacks, or current waves of migrants/refugees, it is beyond doubt that these phenomena are no longer situated in some precise geographic and political space. They are perceived as fluid, global phenomena that do not have a specific locus. There is no simple localization of any problem in the world - everything that happens in one place, in one system, simultaneously produces changes in the environment of that system.

This change in the spatial perspective occurs due to the fact that we are in a situation in which the entire humanity is interacting. "On a planet that is firmly wrapped up by a network of human interdependencies", according to Zygmunt Bauman,

There is nothing else that others can do and for which we can be sure that they will not affect our future, chances and dreams. There is nothing we do, and to say with certainty that it will not affect the future, chances, and dreams of some other people. (Bauman, 2010, p. 115)

The simultaneity and the planetary nature of this interdependence essentially influenced the spatial structuring of the world - all became the center and all became the periphery. This kind of "end of geography" reminds Anthony Giddens, for whom the eradication is "... the rise of social relations from the local contexts and their reconstruction within the unspecified extension of time-space" (Giddens, 1998, p. 30). Although the

Milorad Djurić, Ph.D., Professor, College of Social Work, Speech and Language Therapy and Occupational Therapy (Department of Social Work). 
eradication processes are not exclusively related to modernity, what makes this phenomenon new is that it is also virtual:

Some of us do not have to go out to travel: we can hurry, run, fly through the Internet, grabbing and combining messages on a computer screen that appeared on the opposite sides of the planet. Most of us are on the move even when we are physically immovable. (Bauman, 2003, p. 251)

The territory is, therefore, less an obstacle. The territory is, to a lesser degree, a constituent element of sociality. This is also pointed out by Giddens, for whom globalization is: “... an intensification of social relations on a world-wide scale that connects distant places in a way that local events are shaped by events that have taken miles away and vice versa" (Giddens, 1998, p. 69).

In this sense, not only our experience of the world is changing, the conditions of its analysis are also changing. This means that it is necessary to reconsider the basis of this particularity of the subject area in social theories. The minimum requirement established by this situation is that, if we want to understand these processes, we must correct our current perspective. We must try to analyze the current processes taking into account the world horizon. In doing so, we do not consider the horizon as an objective condition, but as something that lies at the heart of our experience.

Therefore, the basic research question of this paper is: Can the world (and must) be understood as a world society? Our assumption is that the world has become a unique social field and that the world of life $^{1}$ has now become the life of the world, the world as an entire, interdependent reality. In other words: (1) in the modern sense, societies are constituted as relatively closed, self-referential systems, in which the world of social life is framed by the borders of national states; (2) intensifying and extending the process of (global) communication relativizes the boundaries of such closed systems, and this establishes the situation of a global society; and (3) the theoretical and practical political (infra)structure is still fixed on old patterns and lags behind this change, which inevitably creates a deficit of legitimacy in the political field.

Changing the perspective only partially facilitates the task of correcting the previous understanding of political processes, insofar as the center of constituting the social one no longer takes the space framed by the borders of national states. However, to the same extent, the issue of creating a normative order is important in order for this situation to be adequately articulated. World society without proper political structure becomes the cause of a permanent crisis. A radical break-up between society and the state, between real social life and political structures is undoubted: The ultimate picture of this split shows a frustrated citizen who participates in "voting" and "decision-making", and then real decisions are made at other levels. By avoiding the cliché of conspiracy theories, we have to ask the question: How did we get into this situation at all?

\section{Society as a World}

It is necessary to start by considering the concept of society. The concept of society is the most complex concept that left us in the heritage of social and philosophical theories of the 18th, 19th, and 20th centuries. Our understanding of society is shaped by different schools of thought: from the theory of social contract, by which society creates a "treaty" in which individuals, in their relationship, "renounce" their freedoms and their natural rights in order to undermine the state of war of all against all and preserve their own existence; to various

\footnotetext{
${ }^{1}$ Under the "world of life" here we mean "everyday life", that is, social experience, the empirical state of concrete history, a set of concrete social and anthropological conditions.
} 
sociological orientations that have been its object, society, explained as a system similar to living organisms, in which the general principles of organic development apply. In addition, we also understood society as a product of psychological relations between the individual (psychologism); as a system that rests on social action, that is, the behavior of individuals (behavioralism); as a self-regulating and self-sustaining system of interactions of different roles (functionalism); as the relation of individual elements in relation to the structure of the social system (structuralism); or as a permanent conflict of opposing classes (marxism). These are various examples of reflections on the processes of constituting modern societies formed on the ruins of the "old regime", whose basic principle of differentiation rested on the hierarchy of various social stocks. The growth of the functional differentiation of modern societies has initiated various approaches to its own self-description.

However, in the minimum definition of the notion of society, for the purposes of this paper, we can use Parsons's criteria (which, ultimately, rely on Aristotle): "Society is the type of social system in any universe of social systems that attains the highest degree self-sufficiency as a system in relation to its environment" (Parsons, 1988, p. 26). It is therefore clear that society is a restricted, self-contained, self-referential, and self-sufficient system. The self-sufficiency of a society, in this sense, would have to assume the institutionalization of a sufficiently broad spectrum of components in order to respond to all important social demands. This, of course, does not mean that all the roles of all members are played within society, but that a particular society must be able to respond to the elementary demands of its members at different stages of the life cycle.

Besides, in the modern world, after the breakdown of the medieval Christian normative system, the state appears as a functional unity of various institutions, "produced" by society in order to create and implement political decisions. At the same time, society is "produced" by the state as a new basis for the legitimacy of the normative order. This mutual permeation Parsons defines as a societal community:

The core of a society as a system is a structured normative order through which the life of the citizens is organized collectively. As a order, these nuclei contain values as well as the differentiated and specially specified norms and rules, all of which require cultural references to gain meaning and legitimacy. (...) We will call this whole of society, in its collective aspect, a societal community. (Parsons, 1988, p. 29)

The societal community, necessarily, implies functional management of an area, in other words, a rounded territory. "The complex of power-territory-force is of such importance", says Parsons, "that what is commonly understood as a society, if at a high degree of differentiation, in general, on this basis is almost always organized as a single collective, that is, it will be a politically organized society" (Parsons, 2009, p. 216). Territoriality thus becomes an imperative in the process of maintaining the normative order of the societal community.

This, however, came not only to a complete social system, but also to its environment, which is not just "the other", a mere remnant, but at the same time a condition for existence, the assumption of the identity of the social system itself, the basis for the differentiation of the social system and the environment. The constitutive character of the environment in relation to the social system has no absolute character; it is not ontologic, but relative - the result of a differentiation operation, self-observation, which system attributes the characteristics by which it differs from the environment. This attribution, however, is not arbitrary, it is guided by the principle of complexity reduction. Niklas Luhmann insisted on this: "Every system excludes itself from its environment. Therefore, the environment for each system is different. (...) That is why it can be said that leaving the environment uncertain, the system totalize itself" (Luhmann, 2001, p. 258). 
With these operations, the society pulls the boundaries in relation to its own environment, becoming the exclusive space of social experience, the space of the entire and self-sufficient world of life. This withdrawal of the boundaries, this differentiation between the social system and the environment is mediated exclusively by meaningful boundaries. "Meaningful boundaries", Luhmann warned, "are not only outer skin which, as an authority, meets certain functions among others. These boundaries add to the system the elements from which it is composed and reproduced" (Luhmann, 2001, p. 275). And the way in which the boundaries are established is communication.

Every communication in the social system (...) requires differentiation from the environment and thus contributes to determining, that is, to changing the system boundary. Conversely, the boundary assumptions have the function of ordering the constitution of elements; they allow us to evaluate which elements can be built into the system. (Luhmann, 2001, p. 275)

Social production of communication is, therefore, the other side of the social production of borders, especially contributed by the technology of printing, which enabled a type of communication that was significantly different from the previous communication technologies. "The printed book", Marshall McLuhan once said, "an extension of visual power, has strengthened in a psychic way, a perspective and a fixed point of view. In a societal perspective, the typographic extension of man brought nationalism, industrialism, mass markets, universal literacy and education" (McLuhan, 1971, p. 128).

These are processes that, during the 19th and 20th centuries, have created national states. In the process of self-describing their own identity, the specific communities were concentrated in the point of relations between the nation and the society. In this way, an upgrade of simple administrative unity has been realized by creating a common political/national identity. This social self-description is based on the reflexive appropriation of cultural traditions and produces a strongly integrated community, self-sufficient social totality, with a pronounced "we-they" perspective. Sovereignty and territorial integrity as the exclusive power that the national state has over its territory, as the power to maintain order within the borders and to defend those borders from external danger, and to present itself internationally as an equal competitor, will become the criteria for the functioning of each national state.

The emergence of a nation state, after the French Revolution, was a necessity in order to establish a concept in which the society, that is, the nation would provide the necessary legitimacy, instead of the "old regime" based on the divine legitimacy of the kings. In the next 200 years, the nation-state will become the usual way of organizing societies. That is, we use Parsons's terminology, forming the universe of self-sufficient societies/states, totally sovereign in, practically, all dimensions of everyday life. These hyper-integrated structures of society and the state are organized within defined territories, with strongly built identities, formed in the processes of regional, linguistic, and cultural integration. During the 19th and 20th centuries, domination takes over the concept of society articulated through national states.

\section{World as a Society}

There is no doubt that in the integration of society and the state, the process of differentiation of the system/environment (e.g., "we", Serbs, against "them”, Croats, Albanians, Hungarians, etc.) plays a decisive role. As we have already emphasized, this differentiation is not absolute but relative. It represents the correlation of self-observation that puts these differences into social reality, and only within the frames of the boundaries established by communication. This is also logical, because: "The basic process of social systems", 
as Luhmann believed, "which produce the elements from which the systems comprise in these circumstances can only be communication" (Luhmann, 2001, p. 205). However, if the communication process is a universal constituent of the elements of each social system, the fundamental question is what lies at the heart of the change in the types of social systems? The only appropriate answer is - a change in the way of communication. After all, "the process of socio-cultural evolution must be understood as changing and increasing the chances of successful communication". So, if we fully accept this Luhmann's thesis, according to which: "The elementary process that constitutes socially as a special reality is the process of communication" (Luhmann, 2001, pp. 205-206), then any change in the way of making communication necessarily means a change in the way of constituting society.

In this sense, all technological revolutions in the way of transmitting information necessarily have these changes as a consequence. Thus, Talcott Parsons "institutionalizes written languages in culture", called "the border between primitive and transitional societies" (Parsons, 1988). A phonetic letter enabled communication to emerge from the time and spatial framework that demanded the presence. Centuries later, Gutenberg's invention of printing press brought multiplicity, portability, and repeatability - the characteristics announced by the modern era. "Because", as McLuhan suggested, "if it viewed as a stock of notifications, or as a new tool for the rapid return of knowledge, typography has done an end to provincialism and tribal culture, psychically and socially, in space and in time" (McLuhan, 1971, p. 222). Typographic uniformity also influenced the equalization of speech and writing, that is, standardization and consolidation of national languages. The emergence of television, on the other hand, brought a new kind of change. The mosaic form of the television picture was completely different in relation to the press, which implied a high standardization. Television has produced a new psychic structure of the viewer, requiring deep participation and momentum. Like antique mosaics, the television picture was a radical break with a linear print structure. With television, the road to the global village was traced.

However, this path was rounded up only by the final rise of communications over land, territory. In this sense, two events had an epochal significance: the emergence of civil communications satellites and the Internet. Telstar' ${ }^{2}$ first commercial telecommunication satellite, although it had modest performance in relation to today's standards, represented a revolutionary change in the way information was transmitted, a change that would have far-reaching effects on all spheres of life, from collective action to private life of citizens. By establishing satellite communication, the connection between transmitting information and territory has definitely been interrupted. This separation will create preconditions for new forms of personal and social experience. The physical space of the society/state was no longer an obstacle to the dissemination of information. Anthony Giddens drew attention to the extraordinary significance of this technological innovation:

Once you establish a satellite communications network, it means that from any part of the Earth you can communicate with another part, which enables current global communication. In my opinion, this has changed not only the world society, but also in our personal lives, it has produced many changes. (Giddens, 2003, p. 148)

Combined with satellite communications, television created the situation of a global village. On the other hand, the emergence of the Internet made a final break with the linear structure of our civilization. Although it took 20 years to get all available Internet from the original, military version of the communications network, it

${ }^{2}$ Satellite Telstar was launched on May 10, 1962. 
was obvious that we are presenting perhaps the greatest information technology jump in human history so far. In addition, the discovery of the hypertext link (www) by Tim Berners-Lee,

Allowed the texts placed on various computers to be connected in a single continuous navigation. While circulating in the sea of decentralized documents, the user has the impression that in front of him there is a homogeneous, world-wide and infinite object, the web. (Cardon, 2013, p. 15)

The Internet, obviously, is not an ordinary medium and does not allow classifying the traditional typology of mass communication tools. Moreover, the Internet has its own philosophy: While "classical" broadcast media are organized according to the one-toward-all model, the Internet is based on the principle of everyone-to-everyone. This way, the configuration of communication has been irreversibly changed-now everything is in the center and everything is, at the same time, in the periphery. This change is an inevitable consequence of the structure of the Internet. More like a fishing net, than a spider net, the Internet has opened up possibilities for its own permanent linking and extensification. Dominic Cardon pointed to the significance of the network architecture:

That's why creativity was "deployed" to the edges of the Internet, not to its center. The consequences of this choice of architecture is to set up potential innovations at the borders of the Network, in the software and computers connected to it. This ensures that each user has the power to improve, make visible improvements, and pass them on to everyone who thinks they are appropriate. (Cardon, 2013, p. 17)

This kind of "informational republicanism" has enabled an unprecedented culture of exchange among equals, while avoiding centralization, hierarchy, and selection. As in a village, but this time globally, people are again involved in the flow of events, that is, they are involved in the flow of complex information structures. Boundaries, depending on the territory, geographical obstacles (seas, mountains, deserts), or political agreements, have become irrelevant. The final result of social evolution becomes society, world society. "Society today is", said Luhmann, "one-meaning world society (...) A world society that includes all communications in itself, and nothing else and thus has one-meaning boundaries" (Luhmann, 2001, p. 567; p. 551). Therefore, the total horizon of these thoughtful experiences is the world. This actualization of social evolution occurs with every operation of a system that consolidates the experience of the world. This experience implies a closed operational autopoetic social system that can communicate only in itself and through itself, and thus realizes its own actualization. This establishes the requirement for the concept of society to construct an analogous concept of the world, that is, that the notion of society contains itself as the totality of all events, as a whole reality. As summing up of comprehensive social dimensions, these system operations represent an act of self-description which, in fact, builds a picture of a global society. In spite of numerous theories about the loss of meaning in our modernity, such as Lyotard's attitude of "distrust towards meta-narration" (Lyotard, 1988), a global society without that operation could not exist. A self-describing operation at the global horizon level is also possible because a worldwide communication system has been established. The whole of these processes definitely establish the world as a world society.

\section{Some Political Consequences of the Perspective Change}

Global communication creates world society, and world society creates world problems. These problems strongly define the place and role of the modern state. The old international system in which the national state represented the basic framework for solving the problem faces serious challenges: 
Regional boundaries (referring to the borders of national states-M.Đ.) do not have such an operational significance. They are a political convention important for segmental differences of political subsystems of a global society. These are just places where you are showing a passport, or, occasionally, about which reasons for war are being created. It makes no sense to claim that these are separate societies. (Luhmann, 2014, p. 5)

National states are no longer able to be exclusive controllers of social relations, nor are they able to "protect" their citizens from the chain effects of processes going beyond their borders. Ulrich Beck said:

National state is a territorial state: That is, its power is based on life in a particular place, on the control of the rights of citizenship, on current legislation, on the protection of borders, etc. The global society, which, according to the model of globalization, received a form in many (not only economic) dimensions, undermines the importance of a nation state because the borders of a nation-state now oppose a multitude of social circles, communication networks, market relations and lifestyles, and none is inherent in some particular locality. This is evident in each of the pillars: tax collection, police responsibilities, foreign policy, and military security. (Beck, 2003, p. 133)

The idea of closed, self-sufficient societies has become illusory, since no society can be excluded from the influence of others. New global challenges require answers other than those that could be provided by societies that are framed by national states.

The impact of border crossings is followed and encompasses various areas: climate change, ecology, economic flows, social inequality, culture, etc. These are the areas where the most serious structural disorders occur, the most serious social splits, which also affect the creation of different answers in the political field. Their common characteristic is that they have to be looked at from a new perspective. All this relates to the existential assumptions of the old system of societies/states. The reason for this lies in the change of topic and boundary links. In order for the system of social interaction to be held within the boundaries (in other words, to maintain its own meaning), certain topics must be permanently excluded for which the system is simply no longer competent. In this way, the national state system gradually announces it inadequate, continually self-limiting its operability. This reduction in complexity is an attempt to maintain the principle of differentiation. But the differentiation of one system (national state) and its environment (a set of other national states) is becoming less important, as more and more topics become common (global). Because of this, the borders really get a more symbolic meaning, since territoriality becomes a completely untypical principle, the exotic moment of limiting something that is displaced, by its own dynamics, to other levels of real existence.

This reduction of the topics through which the system of society reproduced indicated the emerging need for a different type of organization in order to articulate the newly emerging state. The immediate consequence is the increasing frustration of national states and the steep decline in its regulatory capacities. In fact, the inability of national states to solve global problems is the basic driving mechanism of global governance. This mechanism was, in the main, reflected in the "relieving" of normative centers, that is, in delegating conflicts to supranational levels. However, the problem is not resolved in this way completely, because the supranational level to which these conflicts are delegated does not have its own political order, but it is composed of fragmented organizations, regimes, and informal associations and groups. This level "inhabits" transnational organizations.

Transnational organizations are, therefore, a consequence of globalization, but also a cause and a factor in the further strengthening and dynamization of global connectivity. The tension between national states and transnational organizations is intensified insofar as these organizations (the United Nations, the World Trade Organization, the International Monetary Fund (IMF), the European Union, etc.) continuously extend their 
powers by establishing universal standards for almost all areas of life. In other words, instead of the principle that the legitimacy of the state bases on the fact of the effective possession of public authority, the principle entails that the state legitimacy depends on respecting democratic standards and adherence to certain common values.

The necessity to find new perspectives and new ways of cooperation required the creation of a large number of international organizations. In these, new forms of multilateral and multinational politics, that is, new forms of collective decision-making, include governments, international governmental organizations, pressure groups, and international non-governmental organizations. Concentrated on resource management and the adoption of international regulations, these organizations are increasingly involved in controversial situations. For example, the IMF's financial assistance to national economies is often conditioned by the reduction of public spending, the limitation of wages and employment in the public sector. Also, it implies "good governance", respect for human rights, effective public administration, a liberal democratic mechanism of political responsibility, and so on. The main objections to this version of transnational politics relate to the violation of the sovereign rights of national states and the imposition of political standards without respecting the specific conditions in those societies.

In any case, transnational organizations in the sphere of politics, law, security, social security, and economics are convincing indicators of the situation in which national states are becoming less subject and more object within the globalization process. Also, the activities of transnational organizations are an indication of the fact that a global society does not have its own political order, so that all these actors actually float in one specific area without a consistent normative foundation. Such a lack of normative foundation necessarily produces a deficit of legitimacy. The lack of legitimacy, then, creates situations in which the functioning of transnational organizations seems less like expressing and reproducing any order, and more like the implementation of action programs. In other words, the mentioned type of operation is not placed in well-known normative frameworks, but almost exclusively rests on certain values. It is therefore not surprising that this type of representation of different interests from opponents is interpreted as ideological.

The suspension of the institutional dimension of events at the level of the world society inevitably causes structural tensions that cannot be concealed by any semi-spontaneous equilibrium between national states and transnational actors. Therefore, we should not underestimate the frustrations that arise in response to the action of this amorphous global space. Numerous protests represent the frustration of citizens found in political systems that, objectively, are not functional because their essential political dimension is largely displaced into the area of non-state sovereignty. It is therefore necessary to look at the problem from the perspective of the world horizon. Simply, world society requires a new perspective. This is not a question of choice, but an imperative of the future. From the changed perspective of the global horizon, the only way in which globalization can become democratic is that democracy becomes global.

\section{References}

Bauman, Z. (2003). Turisti i vagabundi (Tourists and vagabounds). In V. Vuletić (Ed.), Globalizacija mit ili stvarnost. Beograd: Zavod za udžbenike i nastavna sredstva.

Bauman, Z. (2010). Fludni strah (Liquid fear). Novi Sad: Mediterran Publishing.

Beck, U. (2003). Virtuelni poreski obveznici (Virtual taxpayers). In V. Vuletić (Ed.), Globalizacija mit ili stvarnost. Beograd: Zavod za udžbenike i nastavna sredstva.

Cardon, D. (2013). Internet demokratija (Internet democracy). Beograd: Fabrika knjiga. 
Giddens, A. (1998). Posledice modernosti (The consequences of modernity). Beograd: Filip Višnjić.

Giddens, A. (2003). Svet koji nam izmiče: prvo predavanje (Runway world-Lecture 1). In V. Vuletić (Ed.), Globalizacija mit ili stvarnost. Beograd: Zavod za udžbenike i nastavna sredstva.

Luhmann, N. (2001). Društveni sistemi (Social systems). Sremski Karlovci: Izdavačka knjižarnica Zorana Stojanovića.

Luhmann, N. (2014). Globalization or world society? How to conceive of modern society. Retrieved from www.generation-online.org/p/fpluhmann2.htm

Lyotard, J. (1988). Postmoderno stanje (Postmodern condition). Novi Sad: Bratstvo-Jedinstvo.

McLuhan, M. (1971). Poznavanje opštila-Čovekovih produžetaka (Understanding media-The extensions of man). Beograd: Prosveta.

Parsons, T. (1988). Društva-Evolucijski i poredbeni pristup. Zagreb: August Cesarec.

Parsons, T. (2009). Društveni sistem i drugi ogledi (The social system and toward a general theory of action). Sremski Karlovci: Izdavačka knjižarnica Zorana Stojanovića. 